\title{
Experimental investigation on possible dependence of plastic zone size on specimen geometry
}

\author{
S. K. Kudari \\ School of Mechanical Engineering, Howard College Campus, University of KwaZulu-Natal, Durban-4041, South Africa. \\ B. Maiti \\ Department of Mechanical Engineering, Indian Institute of Technology, Kharagpur-721 302, India. \\ K. K. Ray \\ Department of Metallurgical and Materials Engineering, Indian Institute of Technology, Kharagpur-721 302, India.
}

\begin{abstract}
In this investigation the extent of the plastic zone size ahead of a crack-tip in single edge notched tension (SENT), compact tension (CT) specimens has been examined experimentally by micro-hardness technique and by elastic-plastic finite element analyses at different applied load levels. The magnitudes of the plastic zone size (PZS), $r_{p}$ ahead of crack-tip in the investigated specimens have been compared using normalized J-integral $\left(\mathrm{J} / \mathrm{a} \sigma_{\mathrm{y}}\right.$, where, a-crack length and $\sigma_{\mathrm{y}}$-yield stress of the material). The results show the dependence of PZS on specimen geometry due to varied in-plane crack-tip constraint. The results also demonstrate that the existing analytical models do not explain the experimental results of PZS satisfactorily.
\end{abstract}

KEYWORDS. Crack-tip plasticity; elastic-plastic material, specimen geometry, micro-hardness technique

\section{INTRODUCTION}

T he studies on crack-tip plastic zones are of fundamental importance in describing the process of failure from a macroscopic viewpoint and in formulating various fracture criteria. The standard ASTM procedure ASTM E182099a [1] for determining fracture toughness criteria of materials require knowledge of the extent of plastic zone occurring at the crack-tips. Wang [2] has suggested that plastic deformation may be the main mechanical driving force for crack propagation. Park et al. [3] have considered that size of crack-tip plastic zone is a potential EPFM parameter connecting direct physical meaning to describe crack propagation. In EPFM, it is also known that the load intensity in ductile fracture measured as J-integral alone cannot describe the stress state accurately. This discrepancy is commonly referred as constraint issues in fracture. Yuan and Brocks [4] have considered that constraint literally is a structural obstacle against plastic deformation, which is induced mainly by geometrical and physical boundary conditions. With detailed finite element analyses they have also argued that constraint effects in a fracture specimen depend on the plastic zone size (PZS). Recently, Kudari et al. [5] have theoretically studied the effect of specimen geometry on plastic zone size using the J-integral to explore the constraint effects. The authors have suggested that the results can be used to obtain a specimen size requirement of $\mathrm{J}_{C}$ test specimen independent of specimen geometry. The theoretical analyses of Kudari et al. [5] related to constraint effects and plastic zones have been carried out on different types of specimen configurations. These results demand substantiation with some experimental measurements of PZS.

A number of investigations are available on the experimental estimation of plastic zones in metallic materials as cited in the article of Uguz and Martin [6]. But, the available results from these investigations cannot be used in a simplified manner to support the theoretical work on PZS presented by Kudari et al. [5]. The details of deformation behaviour together with determination of PZS are required to compare estimates made from theoretical analysis and experimental work. In this study an effort is made to generate experimental and theoretical estimates of PZS pertaining to the same 
material in two specimen geometry having varied a/W ratio to substantiate the theoretical analysis of Kudari et al. [5]. A comparative assessment of the experimental measurements of PZS with the results computed by elastic-plastic finite element analysis (FEA) and earlier analytical formulations $[7,8,9]$ has been also carried out.

\section{EXPERIMENTAL}

A

commercial interstitial free (IF) steel has been selected for experimental determination of plastic zones in the present investigation. The IF steel has been obtained in the form of $3 \mathrm{~mm}$ thick sheets in the cold rolled state as Tab. 1. In the present experimental investigation, micro-hardness technique [6] is used for estimation of plastic zone size. Hence, it was necessary to relieve the surface stresses in the as received material due to cold rolling, and material is given a heat treatment. All specimens of the interstitial free steel for various investigations were subjected to stress-relief annealing. The stress relief annealing consisted of soaking the specimens at $700 \pm 2{ }^{\circ} \mathrm{C}$ for 1 hour in a resistance heating furnace followed by air-cooling. The microstructure of the steel was found to exhibit equiaxed polygonal ferritic structure having average size of $27.1 \pm 2.2 \mu \mathrm{m}$, as determined by linear intercept method. The single-phase structures of this material constitute the selection basis because this makes application of the microhardness technique amenable for determining plastic zone size.

\begin{tabular}{cc}
\hline Element & Weight percentage \\
& \\
$\mathrm{C}$ & 0.003 \\
$\mathrm{Mn}$ & 0.110 \\
$\mathrm{Si}$ & 0.009 \\
$\mathrm{Cr}$ & 0.027 \\
$\mathrm{Ni}$ & 0.017 \\
$\mathrm{Mo}$ & 0.002 \\
$\mathrm{~S}$ & 0.007 \\
$\mathrm{P}$ & 0.012 \\
$\mathrm{Al}$ & 0.040 \\
$\mathrm{Cu}$ & 0.006 \\
$\mathrm{Nb}$ & 0.001 \\
$\mathrm{Ti}$ & 0.055 \\
$\mathrm{~V}$ & 0.001 \\
$\mathrm{~N}$ & $30 \mathrm{ppm}$ \\
$\mathrm{Fe}$ & $\mathrm{Bal}$ \\
\hline
\end{tabular}

Table 1: Chemical composition of the interstitial free steel used in the analysis

Tensile tests following ASTM procedure, ASTM E8-00 [10] were carried out on flat specimens of gauge length $25 \mathrm{~mm}$ and width $10 \mathrm{~mm}$ with the help of a $50 \mathrm{kN}$ capacity screw driven Shimadzu universal testing machine (model: AG5000G) at ambient temperature $\left(30^{\circ} \mathrm{C}\right)$ using a cross head speed of $0.5 \mathrm{~mm} / \mathrm{min}$. The crosshead speed corresponds to nominal strain rate of $3.33 \times 10^{-4} \mathrm{~s}^{-1}$. Two tensile tests were carried out to obtain the average tensile properties of the selected steel. The micro-hardness of the material was determined with the help of a micro-hardness tester (LECO, model: DM400) using a load of $10 \mathrm{gm}_{\mathrm{f}}$ for $15 \mathrm{sec}$ duration. The average micro-hardness value was estimated from 25 randomly taken readings.

Two types of specimens were fabricated for the measurement of plastic zone size. These are: (a) single edge notched tensile (SENT) and (b) compact tension (CT) specimens. All the SENT specimens were fabricated with width (W) $=25$ $\mathrm{mm}$ and height $(\mathrm{H})=100 \mathrm{~mm}$. The value of a/W considered in this study are 0.25 and 0.50 . The CT specimens were made following the ASTM standard [1] with $\mathrm{W}=25 \mathrm{~mm}$ and $\mathrm{a} / \mathrm{W}=0.5$. The specimen surfaces were grinded (before heat treatment) to facilitate a fine polishing, which is needed for measuring microhardness. Because of surface grinding, the final thickness of all the specimens was reduced to $2.7 \mathrm{~mm}$. Typical configurations of SENT and CT specimens used in this analyses are shown in Fig.1. 


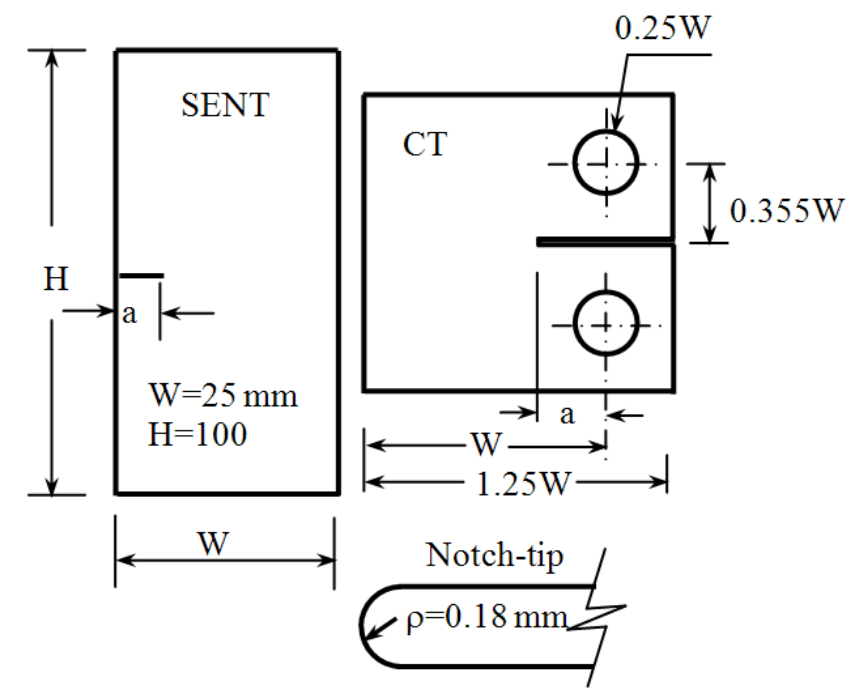

Figure 1: Configurations of SENT and CT specimens used for plastic zone study.

Notches were inserted in the fabricated specimen blanks by wire electro discharge machining (EDM). The notch length in each specimen was measured using the micrometer attached to the specimen stage of the Vickers microhardness testing machine. The configuration of the notch-tip was recorded at X200 with the help of a CCD camera attached to an optical microscope. The notch-tip root radii were then measured from these images with the help of an image analyzer. The notch radius measured was $180 \mu \mathrm{m}$. One side of the specimen was finely polished around the crack-tip in order to facilitate measurements of microhardness and to observe the plastic spread near the crack-tip. This was done by successively grinding the specimen on finer silicon abrasive papers, followed by final polishing on a velvet cloth smeared with $0.25 \mu \mathrm{m}$ diamond paste. Plastic zone in each of the specimens was introduced by applying pre-selected monotonic tensile loads at a crosshead speed of $0.05 \mathrm{~mm} / \mathrm{min}$ at room temperature $\left(30^{\circ} \mathrm{C}\right)$. A number of such tests were carried out on SENT and CT specimens at different tensile loads to introduce varied sizes of plastic zones. The applied tensile loads corresponded to stress ratio $\left(\sigma / \sigma_{\mathrm{y}}\right)$ of 0.4-0.85 for SENT specimens and 0.3-0.75 for CT specimens, where $\sigma$ and $\sigma_{\mathrm{y}}$ are applied stress and yield stress of a material respectively. The applied stress $\sigma$ for SENT and CT specimen have been computed by expressions cited in the earlier investigation of [11].

To evaluate the plastic zone size ahead of crack-tip (at $\theta=0^{\circ}$ plane), a series of micro-hardness indentations were made ahead of each crack-tip with the help of a Vickers pyramid indenter using a load of $10 \mathrm{gm}_{\mathrm{f}}$ for $15 \mathrm{sec}$ duration. The distance between two successive microhardness indentations (during plastic zone estimation) was kept approximately $50 \mu \mathrm{m}$ so that there is no interaction between the deformation zones of the successive indentations. As the material is strain hardening type, because of large strain ahead of the crack-tip the hardness at the tip of the crack is expected to be higher and it gradually decreases as magnitude of strain reduces along the ligament ahead of crack-tip. The micro-hardness tests were terminated at a distance from the crack-tip where the hardness readings were found to have reached a saturation plateau equivalent to the average microhardness value of the material.

\section{FINITE ELEMENT ANALYSIS}

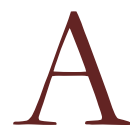
series of stress analyses by finite element method (FEM) have been conducted on single edge notched tension (SENT) and compact tension (CT) specimens (Fig.1) at various applied load steps. All the finite element computations were performed using general-purpose finite element code ANSYS [12]. Due to the symmetry of the specimens under Mode-I loading, only one half of the SENT and CT specimens were considered in the analyses. As specimen thickness is $2.7 \mathrm{~mm}$, it considered to carry out plane stress FE analysis. Two-dimensional FE mesh was generated using eight-noded isoparametric quadrilateral elements, considering plane stress condition with specimen thickness input. The number of elements used for SENT and CT specimens were 1451 and 864 respectively. The load was applied in the form of pressure (uniform applied stress) on the surface parallel to the ligament for SENT specimen. But concentrated point loads were applied for CT specimen model to simulate pin-loading condition in this specimen. 
The sequential developments of plastic zone in the selected specimens were evaluated at different applied loads corresponding to stress ratio $\left(\sigma / \sigma_{\mathrm{y}}\right)$ ranging between 0.1 and 0.85 . The boundary separating the plastic enclave from the elastic bulk was obtained from the iso-stress contours of effective stress $\left(\sigma_{\text {eff }}\right)$ estimated using von Mises yield criterion following the procedure adopted by Gdoutos and Papakaliatakis [13]. The elastic-plastic FE analysis is performed considering the material behavior to be multilinear kinematic hardening pertaining to IF steel. The Newton-Rapson procedure in which stiffness matrix is updated for every equilibrium iterations was used for the nonlinear convergence. In these analyses the elastic modulus and Poisson's ratio of the material has been taken as $194 \mathrm{GPa}$ and 0.3 , whereas the yield strength and the true stress-strain curve were taken from experimental results of tensile test. The plastic part of the true stress-strain curve (Fig.2) was divided into twenty segments for the multilinear hardening model.

The magnitude of J-integral was evaluated for a path at a specific loading condition and for a particular specimen geometry using the expression proposed by Rice [14]

$$
\begin{gathered}
J=\int_{\Gamma}\left(W d y-T_{i} \frac{\partial u_{i}}{\partial x} d s\right) \\
\mathrm{W}=\int_{0}^{\varepsilon} \sigma_{i j} d \varepsilon_{i j} ; T_{i}=\sigma_{i j} n_{j}
\end{gathered}
$$

where

$$
\begin{aligned}
& W=\text { strain energy density, } \\
& T_{i}=\text { traction vector, } \\
& u_{i}=\text { displacement vector, } \\
& s=\text { element of arc length along contour } \Gamma
\end{aligned}
$$

The contour around the crack-tip was defined by four corner nodes in this analysis domain. The average value of $J$ at a particular loading magnitude was estimated by considering four different paths around the crack-tip.

\section{RESULTS AND DISCUSSION}

^

he estimated magnitudes of the tensile properties and hardness of the investigated steels are summarized in Tab. 2. The estimated $2 \%$ yield strength, ultimate tensile strength and percentage of elongation of the investigated steels as indicated in Tab. 2 are in close agreement with some earlier reported results $[15,16]$ for IF steel.

The true stress $(\sigma)$ - true strain $(\varepsilon)$ curve for the investigated material up to a maximum load is shown in Fig.2, which is used for elastic-plastic FE analysis. The experimental determination of plastic zone has been carried out by examining the variation of microhardness with distance ahead of crack-tip along $\theta=0^{\circ}$ plane. A typical plot obtained for SENT specimen with $\mathrm{a} / \mathrm{W}=0.25$ and $\sigma / \sigma_{\mathrm{y}}=0.60$ is shown in Fig.3 in which the average microhardness of the material with its upper and lower bounds are also indicated. The result in this figure indicates that the values of micro-hardness (Vickers hardness, $\mathrm{VH}$ ) continuously decrease with increase in distance ahead of a crack-tip to a saturation plateau. The extent of plastic zone ahead of a crack-tip is considered to be the distance between the location of the crack-tip and the point where microhardness of the material reaches the saturation plateau in microhardness $v s$. distance curve.

\begin{tabular}{cccc}
\hline$\sigma_{\text {ys }}(\mathrm{MPa})$ & $\sigma_{\text {uts }}(\mathrm{MPa})$ & $\% \mathrm{El}$ & $\mathrm{VHN}$ \\
125.40 & 273.10 & 51.12 & 147 \\
\hline
\end{tabular}

Table.2 Mechanical properties of the interstitial free steel used in the analyses.

( $\sigma_{y^{-}}$yield strength, $\sigma_{\text {uts- }}$ ultimate tensile strength, \%El- percentage elongation, VHN Vickers hardness number)

A few earlier investigators $[17,18,19]$ have employed graphical method to locate the boundary of the plastic zone from the microhardness-distance plots. The obtained experimental data of microhardness vs. distance (Fig.3) exhibit considerable scatter, and as a consequence application of the graphical method to demarcate the plastic zone boundary in an unambiguous manner is difficult. A simple analytical procedure was thus developed to locate the boundary of the plastically deformed regimes to overcome the above problem. 


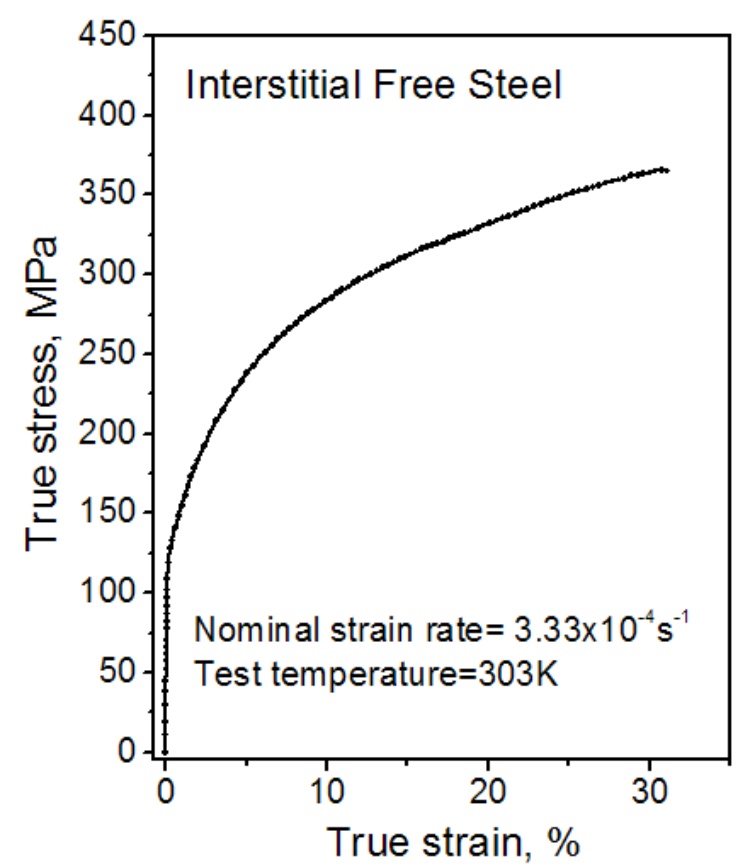

Figure 2: True stress $v s$. true strain curve for investigated IF steel.

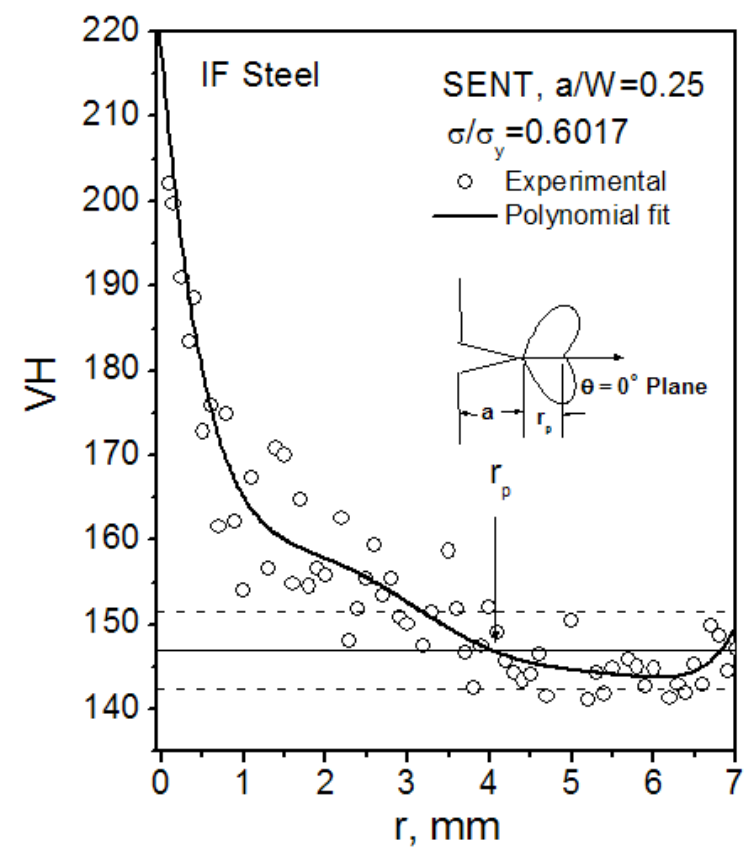

Figure 3: Typical plot of the variations of microhardness values ahead of a crack-tip.

The microhardness values in the saturation plateau were found to fluctuate within some definite limits for the IF steel. The fluctuation of microhardness values of a material is an intrinsic phenomenon; never the less this was examined in the following way. The average microhardness values of these steels were separately determined on unloaded samples. These experiments yielded average microhardness of IF steel $147 \pm 5 \mathrm{VH}$. When the mean value was marked on the microhardness-distance plots, the saturation plateau could be delineated, but the point, which demarcates the elasticplastic boundary, could not be ascertained with certainty. Next, each set of data was subjected to polynomial fit with polynomial equations of different degrees. It was found that as the degree of the polynomial increases, the magnitudes of the regression coefficients also increase. But while carrying out this exercise, it was found that the improvement in the magnitude of the regression co-efficient was marginal for fitted polynomials with degrees greater than six. Hence, a sixth degree polynomial was selected to describe the obtained variation of micro-hardness with distance. Typically, such best-fit curve is also shown in Fig.3.

The first intersection of the sixth degree polynomial with mean value of the saturation plateau was located. The distance between the crack-tip and this point was considered as the extent of plastic zone size $\left(\mathrm{r}_{\mathrm{p}}\right)$ in a specimen as shown in Fig.3. The degree of scatter associated with micro-hardness values measured in plastic zone was found to be $\pm 5 \%$. This scatter of microhardness is in close agreement with the scatter reported by Ray and Mondal [20].

In order to study the effect of specimen geometry and a/W ratio on plastic zone size a few experiments were carried out to reveal the microhardness variation ahead of crack-tip up to the end of ligament. A typical such plot for CT specimen with a $/ \mathrm{W}=0.5$ is shown in Fig.4. It is noted from this figure that microhardness first decreases to a plateau and again increases up to the end of the ligament. The increase of microhardness near the ligament end of the specimen is due to the existence of compressive plastic zone [21] due to bend loading. Because of development of compressive plastic zone in specimens with higher a/W ratio, the growth of crack-tip plastic zone size gets hindered. The development of compressive plastic zone depends on the specimen geometry and loading. Thus it can be concluded that the magnitude of PZS in a material is significantly influenced by the type and the geometry of the specimen selected for the investigation.

The shape of plastic enclaves using FEA has been obtained at different load steps and the extent of plastic zone size, $\mathrm{r}_{\mathrm{p}}$, at $\theta=0^{\circ}$ have been estimated. The method of to estimate the value of $\mathrm{r}_{\mathrm{p}}$ by using FEA outputs of the plastic enclave is discussed elsewhere [5]. The magnitudes of $r_{p}$ estimated by microhardness technique in CT and SENT specimens $(\mathrm{a} / \mathrm{W}=0.50)$ of IF steel were compared with the theoretically estimated magnitudes of $\mathrm{r}_{\mathrm{p}}$ in Fig.5.

This plot helps to infer that the experimental results of PZS are in good agreement with the results estimated by elasticplastic FEA. Commonly, experimentally determined plastic zone sizes are compared with those derived from the existing analytical models $[7,8,9]$. These analytical models use normalized applied stress $\left(\sigma / \sigma_{\mathrm{y}}\right)$ as a reference parameter. The 
variation of $\mathrm{r}_{\mathrm{p}} / \mathrm{a}$ against $\sigma / \sigma_{\mathrm{y}}$ as obtained from these analytical models were also computed and the results are superimposed in Fig.5. It is clear from all the results depicted in Fig.5 that: (a) none of the analytical models satisfactorily explain the present experimental results and (b) elastic-plastic FEA describes the experimental results in the best manner for the entire range of investigation.

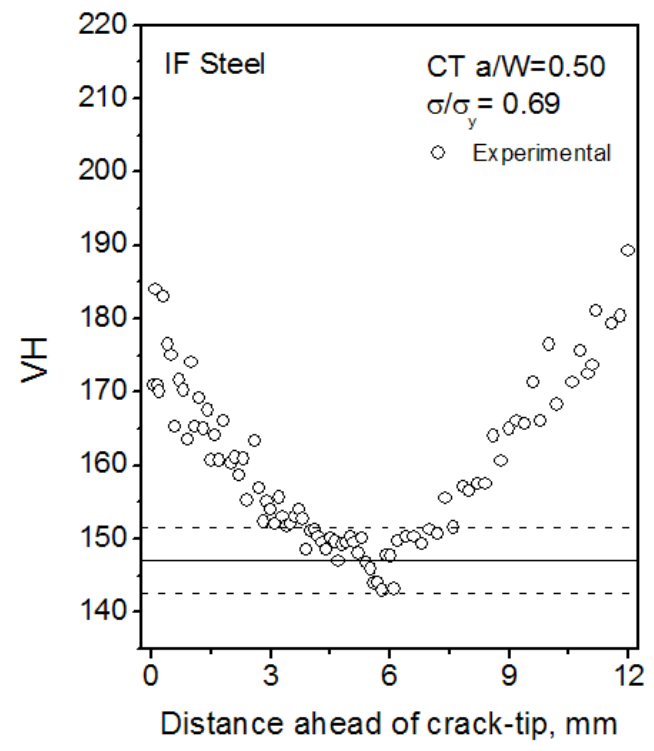

Figure 4: Typical variation of microhardness along the entire ligament of a C'T specimen.

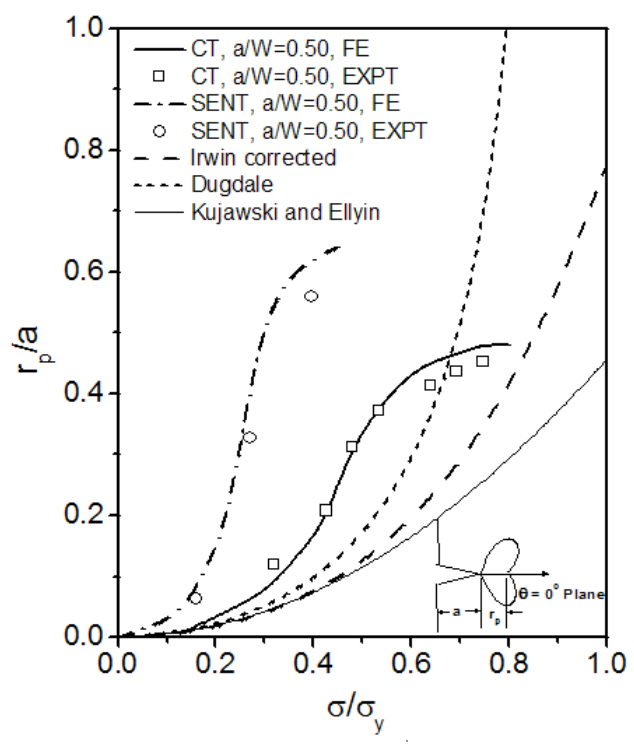

Figure 5: Comparison of the experimental and FEA results with various analytical methods.

All the experimental results on PZS evaluated in the present investigation on IF steel along with the FE results are compiled based on normalized $\mathrm{J}\left(\mathrm{J} / \mathrm{a} \sigma_{\mathrm{y}}\right)$ and normalized $\sigma\left(\sigma / \sigma_{\mathrm{y}}\right)$ in Fig. 6 and Fig.7 respectively. These figures shows that the experimental results are in good agreement with the $\mathrm{FE}$ results plotted against both the reference parameters. These plots infer that the experimental results of PZS are in excellent agreement with the results of FEA when examined with respect to any of the reference parameters at lower applied stress or J-integral levels. At higher applied stress or J levels it is observed that experimental measurements of PZS are marginally lower than that of FEA in the investigated steel. This may be possibly attributed to the following reasons: (i) interaction of compressive plastic zone with the crack-tip plastic zone and (ii) measurement difficulties.

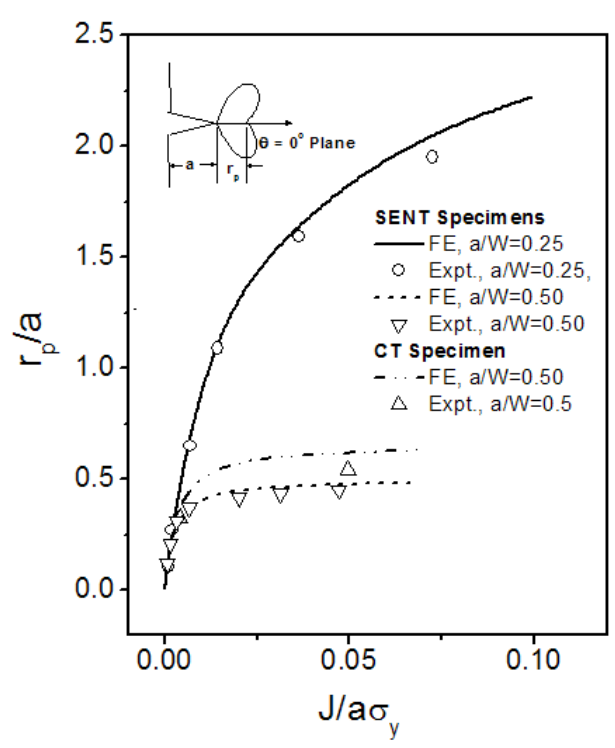

Figure 6: Variation normalized plastic zone size $\left(\mathrm{r}_{\mathrm{p}} / \mathrm{a}\right)$ estimated by microhardness technique and FEA $v$ s. normalized J-integral $\left(\mathrm{J} / \mathrm{a} \sigma_{\mathrm{y}}\right)$ in SENT and CT specimens

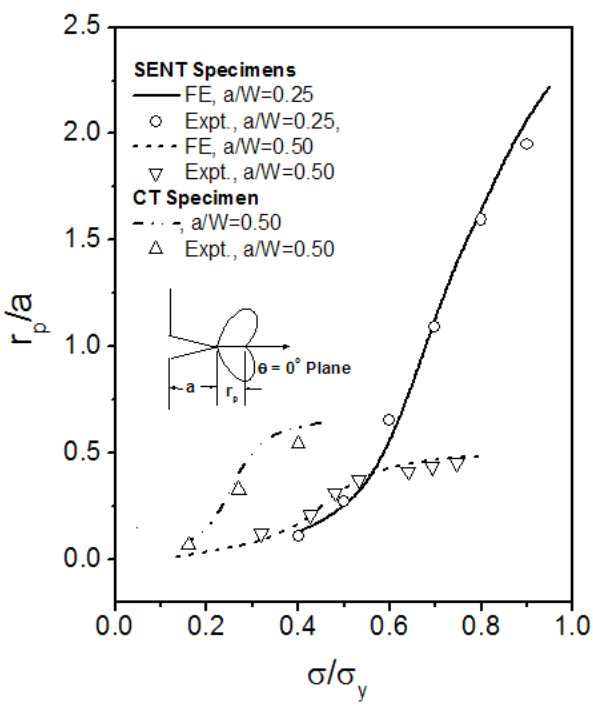

Figure 7: Variation normalized plastic zone size $\left(\mathrm{r}_{\mathrm{p}} / \mathrm{a}\right)$ estimated by microhardness technique and FEA $v s$. normalized applied stress $\left(\sigma / \sigma_{\mathrm{y}}\right)$ in SENT and CT specimens. 
The conventional analysis based on applied stress (Fig.7) illustrates that there is good amount of deviation in the results on different specimen geometry, which does not allow one to satisfactorily explain the effect of geometry on PZS. On the other hand, the variation of $r_{p} / a$ with $J / a \sigma_{y}$ (Fig.6) shows that the nature of growth of PZS in the two types of specimens in both the investigated steels is almost identical up to a particular magnitude of $\mathrm{J} / \mathrm{a} \sigma_{\mathrm{y}}$, beyond which the specimen geometry influences the nature of variation of $\mathrm{r}_{\mathrm{p}} / \mathrm{a}$, as obtained in the investigation of Kudari et al. [5]. The critical value of up to which $\mathrm{r}_{\mathrm{p}} / \mathrm{a}$ is similar in SENT and CT specimens is $\cong 0.0035$. These results elucidate that the development of plastic zone size in a specimen is primarily affected by the specimen geometry and a/W ratio due to varied in-plane constraint [4]. The present experimental results on PZS thus validate the theory proposed by Kudari et al. [5] that the study of plastic zones made with respect to normalized $\mathrm{J}\left(\mathrm{J} / \mathrm{a} \sigma_{\mathrm{y}}\right)$ yield better analysis of the results. The PZS results studied in this manner gives clear idea of geometry dependency and can be used for constraint analysis and to obtain specimen size requirements for fracture test independent of geometry.

\section{CONCLUSIONS}

$\mathrm{I}$ $\mathrm{n}$ this work a simple procedure for demarcating the location of elastic-plastic boundary in the microhardness vs. distance plot ahead of a crack-tip has been suggested. It has been shown that the experimental results of PZS for interstitial free steel are in excellent agreement with the elastic-plastic FE analysis. The experimental results obtained validates the theoretical investigation of Kudari et al. [5], which can be used for to obtain specimen size requirements for fracture test independent of geometry.

\section{ACKNOWLEDGEMENTS}

One of the present authors Dr S. K. Kudari would like to thank the Department of Materials and Metallurgical Engineering, Indian Institute of Technology, Kharagpur, India, for providing Laboratory facilities to carry out this work.

\section{REFERENCES}

[1] ASTM E1820 -99a, 1999. Standard test method for measurement of fracture toughness, American Society for Testing and Materials, Philadelphia.

[2] G. S. Wang, Engineering Fracture Mechanics, 46 (1993) 909-930.

[3] Park, Heung-Bae, Kim, Kyung-Mo, Lee, Byong-Whi., International Journal of Pressure Vessels \& Piping, 68 (1996) $279-285$.

[4] H. Yuan, W. Brocks, Journal of the Mechanics Physics Solids, 46 (1998) 219-241.

[5] S. K. Kudari, B. Maiti, K.K. Ray, Journal of Strain Analysis for Engineering Design, 42 (2007) 126-137.

[6] A. Uguz, J. W. Martin, Materials Characterization, 37 (1996) 105-118.

[7] G.R. Irwin, Proc 7th Sagamore Ordinance Mater. Res. Conf., New York, IV (1960) 63-77.

[8] D.S. Dugdale, Journal of the Mechanics Physics Solids, 8 (1960) 100-104.

[9] D. Kujawski, F. Ellyn, Engineering Fracture Mechanics, 25 (1986) 229-236.

[10] ASTM E8-00, 2000. Standard test method for tension testing of metallic materials, American Society for Testing and Materials, Philadelphia, Pennsylvania.

[11] A.H. Priest, Journal of Strain Analysis for Engineering Design, 10 (1975) 225-232

[12] ANSYS Version 9, 2004. Swanson Analysis Systems, ANSYS Inc., Canonsbarg PA, USA

[13] E.E. Gdoutos, G. Papakalitakis, International Journal of Fracture, 32 (1987) 143-156.

[14] J.R Rice, Journal of Applied Mechanics Transactions of ASME, 35 (1968) 379-386.

[15] R. Mendoza, M. Alanis, J. Huante, C. Gonzalez-Rivera, J.A. Juarez-Islas, Journal of Materials Processing and Technology, 101 (2000) 238-244.

[16] R. Mendoza, M. Alanis, J. Huante, C. Gonzalez-Rivera, J.A. Juarez-Islas, Materials Science and Engineering A, 276 (2003) 203-209.

[17] C. Bathias, R.M. Pelloux, Metallurgical Transactions, 4 (1973) 1265-1273.

[18] S.I. Kwun, S.H. Parks, Scripta Metallurgica, 21 (1987) 797-800.

[19] C. Loye, C. Bathias, D. Retali J. C. Devux. ASTM-STP 811 (1983) 427-444. 
[20] K.K. Ray, D. Mondal, Metallurgical Transactions, 23A (1992), 3309-3315.

[21] R.H. Dodds Jr, T.L. Anderson, M.T. Kirk, International Journal of Fracture, 48 (1991) 1-22. 